
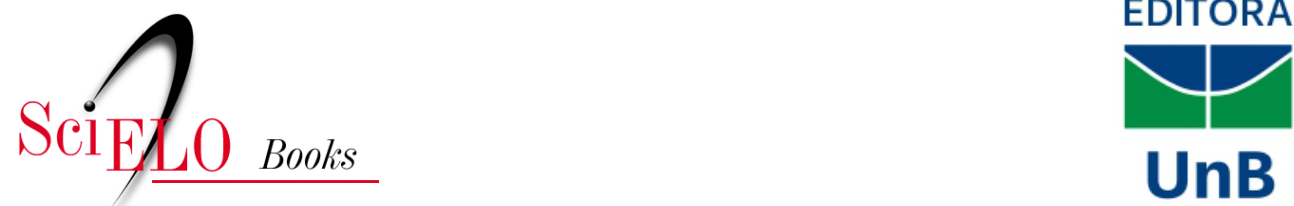

UnB

\title{
Capítulo 4 - Para além do gabinete: o ativismo de procuradores no caso da Usina de Belo Monte
}

\author{
Luiz Henrique Vilaça
}

\section{SciELO Books / SciELO Livros / SciELO Libros}

VILAÇA, L. H. Para além do gabinete: o ativismo de procuradores no caso da Usina de Belo Monte. In: ABERS, R. N., ed. Ativismo institucional: criatividade e luta na burocracia brasileira [online]. Brasília: Editora UnB, 2021, pp. 155187. ISBN: 978-65-5846-159-3. https://doi.org/10.7476/9786558461593.0005.

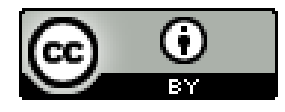

All the contents of this work, except where otherwise noted, is licensed under a $\underline{\text { Creative }}$ Commons Attribution 4.0 International license.

Todo o conteúdo deste trabalho, exceto quando houver ressalva, é publicado sob a licença Creative Commons Atribição 4.0.

Todo el contenido de esta obra, excepto donde se indique lo contrario, está bajo licencia de la licencia Creative Commons Reconocimento 4.0. 


\section{Capítulo 4}

\section{Para além do gabinete: \\ $\mathrm{o}$ ativismo de procuradores no caso da Usina de Belo Monte ${ }^{1}$}

Luiz Henrique Vilaça

\section{Introdução}

Existe uma crescente preocupação em torno de ativistas que operam dentro de instituições (BANASZAK, 2010; PETTINICCHIO, 2012; ABERS, no prelo). Apesar de diversos estudos sobre os efeitos que esses ativistas têm em políticas públicas (RICH, 2013; ABERS; TATAGIBA, 2015; HYSING; OLSSON, 2017), os processos por meio dos quais burocratas se tornam ativistas foram pouco estudados. Neste capítulo, exploro

1 Agradeço os comentários e conselhos de Rebecca Abers, Marisa von Bülow, Carla Teixeira, Erin McDonnell, Terry McDonnell, Ann Mische, Rory McVeigh, Débora Rezende, Luciana Tatagiba e membros do grupo Repensando as Relações entre Sociedade e Estado (Resocie) e do grupo Studies in Politics and Movements. 
esse problema a partir de um estudo de caso sobre procuradores do Ministério Público Federal (MPF) no processo de formulação e implementação da usina hidrelétrica de Belo Monte (BM).

O Ministério Público (MP) é uma instituição intrigante. De apêndice do Poder Executivo e advogado do Estado, o órgão se tornou, no final do último século, independente - um “quarto poder” do Estado - e responsável pela defesa de interesses de grupos sociais diversos (COSLOVSKY, 2009). Procuradores se envolvem constantemente em disputas políticas, sendo chamados inclusive de "agentes políticos da lei” (ARANTES, 2002); no entanto, eles são incentivados a se comportarem de maneira cautelosa e a esconderem motivações políticas (COSLOVSKY, 2009). Além disso, grande parte deles (49\%) prioriza o trabalho mais tradicionalmente entendido como o papel do MP (investigações criminais), enquanto apenas 4\% dá prioridade para a defesa de minorias étnicas (LEMGRUBER et al., 2016). Neste trabalho, investigo a atuação de procuradores em conflitos étnicos e ambientais no caso da usina de Belo Monte (2001-2016).

A usina hidrelétrica de $\mathrm{BM}^{2}$ - localizada no rio Xingu, próximo à cidade de Altamira, no Pará - emergiu na agenda de agências estatais no Brasil na década de 1970 frente ao aumento do preço do petróleo no mercado internacional (DÓRIA, 1976). Desde o princípio, Belo Monte (que na época tinha o nome de Kararaô) foi extremamente contestada por atores diversos - como povos indígenas, organizações de movimentos sociais (OMS) e membros da comunidade acadêmica - devido aos possíveis impactos no ecossistema e nas comunidades locais (MAGALHÃES; HERNANDEZ, 2009). A mobilização intensa em torno da hidrelétrica - que culminou com um grande protesto em 1989, o $1^{\circ}$ Encontro das Nações Indígenas do Xingu - acabou levando o Banco Mundial, então financiador do projeto, a recuar, deixando os planos para a construção de Belo

2 Belo Monte foi apresentada como uma das três maiores hidrelétricas do mundo em termos de potência instalada, com 11.233 Megawatts (MW). Não há consenso, no entanto, em torno da capacidade efetiva da usina, uma vez que, devido à redução do reservatório em alguns períodos do ano, a capacidade instalada só seria "alcançada apenas por três meses no ano” (PEREIRA, 2014, p. 126). De acordo com Bermann (2012, p. 8), a capacidade média da usina deve girar em torno de 4.428 MW por ano. 
Monte engavetados por alguns anos (PEREIRA, 2014, p. 121). Durante a década de 1990, novos estudos foram realizados e um projeto revisado foi apresentado pela Eletronorte (BERMANN, 2012). A partir de então, Belo Monte passou a ganhar um lugar importante na agenda de diversas instituições estatais e foi aprovada no Congresso Nacional em 2005, teve seu licenciamento ambiental iniciado no ano seguinte e seus direitos de construção arrematados pelo consórcio Norte Energia ${ }^{3}$ em 2010. Ainda em meio a protestos, a usina foi inaugurada em $2015 .{ }^{4}$

O MPF começou a se envolver no caso em 2001, quando foi ajuizada uma primeira Ação Civil Pública (ACP) transferindo a competência do licenciamento ambiental da usina para um órgão federal (o Ibama). Desde então, o MPF vem sendo um dos atores mais presentes nas disputas canalizadas pela usina, tanto a partir de ações judiciais como extrajudiciais. As informações coletadas nesta pesquisa revelam que havia grandes diferenças entre os procuradores envolvidos no caso. Parte dos procuradores entendia a defesa de comunidades afetadas como o cerne de seu trabalho e lutava proativamente para defendê-las. Outros procuradores, no entanto, se apresentavam como atores "neutros” e “objetivos”, cuja função era somente a de fiscalizar o cumprimento da lei, e geralmente se restringiam aos instrumentos convencionais que um procurador tem à sua disposição.

Chamo esses procuradores, respectivamente, de ativistas e protocolares. ${ }^{5}$ Inspirado na definição de ativismo em Abers (2019) como "um

3 A Norte Energia (NE) representa o consórcio que ganhou o leilão da usina de Belo Monte - realizado pela Agência Nacional de Energia Elétrica (Aneel) em 2010.

4 Para mais informações sobre o histórico de implementação da usina, ver Pereira (2014).

5 A insistência dos procuradores em questionar a usina levou alguns deles a serem acusados de "ativistas". De acordo com entrevistados, trata-se de uma estratégia para deslegitimar e descreditar a ação dos procuradores (Entrevista 21, MPF, 2016; Entrevista 79, MPF, 2017). É importante ressaltar que o argumento desenvolvido neste trabalho de que procuradores constroem compromissos com causas não compartilha desta crítica. O caráter compromissado das ações dos procuradores não é considerado aqui como um desvio de sua atuação, mas como uma evidência de que o engajamento com causas não opera somente nas esferas da sociedade - e que a ideia de um Estado "neutro" e "imparcial” se desmancha na ação de servidores culturalmente situados (CASTILHO; LIMA; TEIXEIRA, 2014). 
certo tipo de ação que envolve a busca de oportunidades para defender causas contenciosas", mostro como esses dois tipos de procuradores variam crucialmente em (pelo menos) duas dimensões: $i$ ) o tipo de ideias que motivam os atores e ii) os tipos de táticas que acionam. Vale esclarecer que essa distinção pode ser melhor compreendida enquanto continuum e não como uma dicotomia. Procuradores ativistas não são sempre ativistas, assim como procuradores protocolares não se comportam dessa maneira o tempo todo. Procuradores "ativistas" e "protocolares” funcionam como tipos ideais - recursos analíticos que nos ajudam a compreender a realidade (WEBER, 1978). A pergunta central que este trabalho busca responder é: por que alguns procuradores se tornam ativistas e outros não?

Para responder a esta pergunta, lanço mão de três fontes de dados: i) 25 ações civis públicas; ii) 82 entrevistas semiestruturadas com atores-chave; e iii) observação de reuniões, em sua maioria entre procuradores e grupos atingidos e/ou OMSs. Mostro neste capítulo que a maior parte dos procuradores ativistas se tornou ativista após entrar no MPF. Em outras palavras, trata-se de um caso em que o efeito de self-selection tem baixo poder explicativo. Mostro ainda que o ethos organizacional do MPF no Pará, apesar de incentivar o ativismo de procuradores, não era condição suficiente para engajamento no ativismo, visto que procuradores situados nesse mesmo contexto organizacional tomaram rumos bastante diferentes. Argumento neste capítulo que procuradores se tornaram ativistas à medida que interagiam com comunidades afetadas pelo empreendimento e com movimentos sociais locais. Mais especificamente, argumento que por meio de práticas comunicativas, nas quais procuradores descobriam os problemas enfrentados por esses grupos e mediavam seus conflitos com tomadores de decisão da usina, procuradores internalizavam as demandas desses grupos, criando e fortalecendo compromissos com suas causas.

Este capítulo está dividido em seis seções, além desta introdução. Primeiro, reflito sobre a literatura de ativismo institucional e desenvolvimento de compromissos. Na segunda seção, apresento brevemente a trajetória do Ministério Público no Brasil, buscando reconstruir os processos que dão origem a esse órgão “defensor da sociedade” (ARANTES, 2002). Na seção seguinte, ilumino as diferenças no envolvimento entre procuradores ativistas e procuradores protocolares no caso de Belo Monte. Na quarta 
seção, explico o papel das trajetórias e do ethos organizacional do MPF no engajamento de procuradores com causas de grupos atingidos. Posteriormente, discuto como interações de descobertas e mediações desenvolviam e solidificavam o compromisso de procuradores. Por fim, apresento breves considerações finais onde resumo o argumento do capítulo e comento sobre possíveis linhas de pesquisas futuras.

\section{Ativismo dentro de instituições}

Existe uma crescente literatura em torno do papel de ativistas dentro de instituições. De fato, vimos surgir nos últimos anos uma variedade de termos para definir esses atores, tais como "inside activists" (BANASZAK, 2010; HYSING; OLSSON, 2017), “institutional activists” (SANTORO; MCGUIRE, 1997; PETTINICCHIO, 2012; ABERS; TATAGIBA, 2015), “activist bureaucrats” (RICH, 2013), “workplace activists” (SCULLY; SEGAL, 2002; RAEBURN, 2004), “tempered radicals” (MEYERSON; SCULLY, 1995) e “guerrilla governments” (O’LEARY, 2014). Estes autores se apoiam em diferentes definições; neste capítulo, sigo a proposta de Abers (2019) de conceitualizar ativistas institucionais a partir de duas dimensões: o tipo das ideias dos atores e as ações que eles promovem. Para ela, o ativismo é definido primeiramente pelo compromisso com uma causa - uma ideia que "da perspectiva de quem a defende, precisa ser protegida contra forças poderosas de estabilidade ou mudança” (ABERS, 2019, tradução nossa $)^{6}$ - e por um comportamento proativo ou criativo. De uma maneira geral, o principal foco desse grupo de pesquisadores tem sido investigar como burocratas ativistas influenciam políticas públicas (SANTORO; MCGUIRE, 1997). No entanto, pouca atenção tem sido dedicada à compreensão de como e por que alguns burocratas se tornam ativistas.

Uma primeira hipótese é que esses servidores já adentram instituições com compromissos prévios ou disposição para o ativismo, “carregando

6 “[...] from the perspective of believers, needs to be defended against powerful forces of either stability or change.” (ABERS, 2019). 
esse ativismo para dentro de suas carreiras” (GAGNE, 1996, p. 90, tradução nossa). ${ }^{7}$ Estudos precedentes encontraram evidência de self-selection (EISENSTEIN, 1989; RAEBURN, 2004; BANASZAK, 2010; ABERS, 2019). Banaszak (2010, p. 76, tradução nossa), por exemplo, notou que a maioria das ativistas radicais "já eram fortes feministas quando entraram no governo”. ${ }^{8}$ Similarmente, Hysing e Olsson (2017, p. 82, tradução nossa) argumentam que "em grande medida, pessoas já tem suas crenças e valores políticos definidos quando entram em uma organização”. ${ }^{9}$ Na literatura de movimentos sociais, uma das explicações para o engajamento no ativismo são as disposições que os indivíduos desenvolvem em suas trajetórias. Estudos apontam que experiências de vida (MISCHE, 2008) e participação em atividades promovidas por organizações de movimentos sociais, como protestos e ocupações (HIRSCH, 1990; GAMSON, 1991) podem levar a um comportamento ativista. O ponto central aqui é que essa variedade de experiências pode criar uma disposição para o ativismo (SILVA; RUKOWSKI, 2016).

Uma segunda hipótese se refere ao contexto organizacional no qual burocratas estão inseridos. Para alguns autores, organizações socializam atores de maneiras distintas, que podem levar ao desenvolvimento de compromissos (SCULLY; SEGAL, 2002). Afinal, "experiências de trabalho influenciam sistemas de crenças” (HOOGHE, 1999, p. 441, tradução nossa), ${ }^{10}$ visto que "organizações trabalham na socialização dos seus membros [...] possibilitando que indivíduos se identificam com determinados papéis” (FILLIEULE, 2010, p. 7, tradução nossa). ${ }^{11}$ Essa socialização pode ocorrer, por exemplo, por meio de "habitats organizacionais (grupos formais e redes informais)”, nos quais ativistas delineiam estratégias de ação e

7 "[...] feminists achieved their goals by carrying their activism into their careers." (GAGNE, 1996, p. 90).

8 "[...] were usually already strong feminists when they entered government." (BANASZAK, 2010, p. 76).

9 "Beliefs, values, and conceptions are certainly formed outside organizations to a large extent.” (HYSING; OLSSON, 2017, p. 82).

10 “Experiences in the workplace influence belief systems.” (HOOGHE, 1999, p. 441).

11 "Organizations also do a lot of work in socializing their members [...] which allows individuals to identify the different roles they face." (FILLIEULE, 2010, p. 7). 
compartilham experiências (KATZENSTEIN, 1998, p. 19, tradução nossa). ${ }^{12}$ Hysing e Olsson (2017, p. 83) apoiam (pelo menos em parte) esse argumento, notando que "algumas normas, valores e preferências são ajustadas e formadas por meio do envolvimento de indivíduos em organizações” (tradução nossa; ver também COSLOVSKY, 2011). ${ }^{13}$

Uma terceira hipótese foca nas interações estabelecidas pelos burocratas. Aqui, o mecanismo de engajamento no ativismo parece se sustentar em como ativistas são influenciados por seus “colegas das ruas” (RAEBURN, 2004, p. 39), que podem mobilizar atores dentro de instituições e persuadi-los a acreditar nos objetivos que promovem (BINDER, 2002, p. 222). O engajamento no ativismo é visto aqui como um processo intrinsicamente coletivo, porque "apesar da motivação estar enraizada em características psicológicas individuais, ela é construída e desenvolvida a partir de interações” (MELUCCI, 1989, p. 31, tradução nossa). ${ }^{14}$ Melucci (1989, p. 31) argumenta ainda que, por meio de interações, indivíduos "influenciam uns aos outros, negociam, e assim estabelecem frameworks conceituais e motivacionais para agir” (tradução nossa). ${ }^{15}$ Estudos anteriores evidenciaram que ativistas, em diversos momentos, se engajam em redes com organizações de movimentos sociais (BANASZAK, 2010; RICH, 2013; ABERS; TATAGIBA, 2015). Contudo, os processos por meio dos quais essas interações levam ao desenvolvimento de compromissos permanecem pouco claros.

12 “[...] organizational habitats (formal groups and informal networks).” (KATZENSTEIN, 1998, p. 19).

13 “[...] some norms, values, and preferences are adjusted and formed through individuals' involvement with organizations.” (HYSING; OLSSON, 2017, p. 83).

14 "While motivation is rooted in individual psychological traits, it is constructed and developed through interaction.” (MELUCCI, 1989, p. 31).

15 “[...] individuals interact, influence each other, negotiate and hence establish conceptual and motivational frameworks for action." (MELUCCI, 1989, p. 31). 


\section{Métodos}

O caso de Belo Monte emerge como cenário ideal para entender porque alguns burocratas se engajam em causas e outros não, visto que ele amplia a distância na variável dependente que busco explicar ao analisar casos de procuradores não compromissados e procuradores altamente compromissados. Para responder à pergunta de como alguns procuradores se tornaram ativistas, utilizei três fontes de dados. Primeiramente, analisei todas as ações judiciais ajuizadas pelo MPF no caso de Belo Monte entre 2011 e 2016 ( $\mathrm{N}=25)$, cuja maioria era composta por ações civis públicas (ACPs), um "instrumento jurídico que permite a representação, junto ao Poder Judiciário, de interesses coletivos, difusos e individuais homogêneos" (KERCHE, 2007, p. 274-275) ${ }^{16}$ Essas ações foram classificadas com base nas demandas de procuradores e nos argumentos usados para justificar essas demandas. Tais documentos me ajudaram a situar o quão central seria a defesa de comunidades impactadas na agenda de procuradores, bem como a entender os enquadramentos pelos quais procuradores tratavam esses grupos, e as ações que eles promoviam para defendê-los.

Como eu buscava entender as motivações, os valores e as práticas (PUGH, 2013, p. 50) de procuradores, também conduzi 82 entrevistas ao longo de um período de seis anos (2012-2018). As entrevistas foram conduzidas em formato semiestruturado e duraram em média 1-2 horas. Todas as entrevistas (à exceção de duas) foram gravadas e transcritas, com a permissão dos entrevistados. Uma vez que minha população de interesse não era grande, e porque procurei identificar casos que contrariassem o que eu buscava explicar (BECKER, 1998, p. 123), tentei entrevistar o maior número de procuradores possível. Primeiramente, compilei uma lista com todos os procuradores que assinaram ACPs no caso de BM (17). Entrei em contato com todos eles, e consegui entrevistar doze (dos quais cinco foram

${ }^{16}$ Vinte e duas das ações eram ações civis públicas. Duas outras eram ações de improbidade administrativa e uma era uma ação cautelar. 
entrevistados duas vezes) ${ }^{17}$ Entrevistei sete procuradores do escritório de Altamira, três de Belém e dois de Brasília.

Também entrevistei membros de comunidades afetadas $(\mathrm{N}=12)$ e de organizações de movimentos sociais $(\mathrm{N}=32)$, duas lideranças foram entrevistadas duas vezes, e uma delas três vezes. Fiz uma lista inicial de todas as OMSs envolvidas no caso de Belo Monte por meio de cartas públicas enviadas a autoridades e de estudos anteriores desenvolvidos sobre o caso (PEREIRA, 2014). As entrevistas remanescentes foram selecionadas via snow-ball (WEISS, 1995), ou seja, por meio de perguntas aos entrevistados sobre outras organizações envolvidas com o caso de Belo Monte que eu poderia entrar em contato. Um procedimento similar foi feito para estabelecer quais agentes estatais - além dos procuradores - seriam entrevistados. Consegui entrevistar 13 atores estatais, incluindo servidores do Ibama, da Fundação Nacional do Índio (Funai) e do Instituto Nacional de Colonização e Reforma Agrária (Incra) e da Defensoria Pública (da União e do estado do Pará). Finalmente, também entrevistei pesquisadores que colaboraram com o MPF $(\mathrm{N}=5)$ e um funcionário da Norte Energia. Os nomes dos entrevistados foram suprimidos para preservar sua identidade. Destarte, ao citar falas de entrevistados apenas listo o número da entrevista e (quando aplicável) a organização a qual o indivíduo faz parte.

De modo a triangular as informações obtidas nas entrevistas (TAYLOR; BOGDAN; DE VAULT, 1998), também observei quatorze reuniões (que duraram entre $1 / 2$ e 2 horas). Sete delas envolveram procuradores e organizações de movimentos sociais e/ou comunidades afetadas. Atores estatais de outros órgãos estiveram presentes em três dessas reuniões. O restante dessas reuniões ocorreu na Defensoria Pública (2), e entre organizações de movimentos sociais (5). A observação participante foi fundamental para comparar o que procuradores diziam que faziam com o que eles efetivamente praticavam (JEROLMACK; KHAN, 2014). Uma importante limitação deste estudo, no entanto, é que apenas consegui observar reuniões de um dos procuradores.

${ }^{17}$ Vale notar que nem todos os procuradores estavam trabalhando ativamente no caso de $\mathrm{BM}$ no momento em que foram entrevistados. Muitos deles haviam trabalhado no caso no passado e mudado de estado e/ou temática posteriormente. 


\section{Os meninos superpoderosos e a autonomia do MPF}

Em 2007, uma reportagem na revista Época comparou procuradores brasileiros à série de TV “As Meninas Superpoderosas”, na qual três meninas usam superpoderes para lutar contra vilões e proteger sua cidade. Esse artigo criticava as constantes intervenções de procuradores em projetos de energia, argumentando que "jovens com autonomia garantida por lei, os procuradores do Ministério Público mostram sua força e atravancam a infraestrutura do país” (PAUL, 2007).

O Ministério Público é realmente uma instituição singular no Estado brasileiro, principalmente após sua reforma institucional no final do último século. Uma série de leis durante as décadas de 1970 e 1980 - incluindo a Constituição Federal de 1988 - empoderaram significativamente procuradores, ao conferir-lhes "alto grau de independência funcional e controle completo sobre as ações que conduzem” (ARANTES, 2007, p. 329), abrindo a porta para que eles atuem como "agentes políticos da lei” (ARANTES, 2002, p. 80). As atribuições de procuradores visivelmente extrapolam a área criminal, visto que procuradores atuam em uma variedade de temáticas, "incluindo preservação ambiental, direitos de minorias, saúde pública, entre outras” (COSLOVSKY, 2011, p. 73, tradução nossa). ${ }^{18}$

Apesar de, formalmente, procuradores do MP possuírem a liberdade para se engajar em diversos conflitos políticos, pesquisas prévias revelam que a instituição cria uma variedade de incentivos para que os procuradores sejam cautelosos - isto é, justamente para que não se transformem em ativistas. O processo de seleção da organização, que consiste em uma série de exames, na prática avalia "se os candidatos se vestem de maneira apropriada e apresentam comportamento conservador, se eles escondem filiações políticas, e demonstram respeito a autoridade" (COSLOVSKY, 2011, p. 76-77, grifo nosso, tradução nossa). ${ }^{19}$ Esse processo de socialização

18 "[...] including environmental preservation, minority rights, public health, and more." (COSLOVSKY, 2011, p. 73).

19 "[...] whether candidates dress and behave conservatively, hide political affiliations, demonstrate unwavering respect for authority.” (COSLOVSKY, 2011, p. 76-77, grifo nosso). 
continua quando candidatos recebem treinamento e começam a trabalhar, visto que "a maioria das políticas gerenciais adotadas pelo MP prioriza diligência e consistência ao invés de criatividade, e cautela e processamento de casos no lugar de resolver problemas criativamente" (COSLOVSKY, 2011, p. 75-76, tradução nossa). ${ }^{20}$

Dentro desse ambiente organizacional, contudo, existem diferentes tipos de procuradores, que foram classificados em duas categorias por pesquisas anteriores: de um lado, o promotor $^{21}$ de fatos, que

indica a tendência de alargamento das funções dos promotores para muito além da esfera jurídica, tornando-os verdadeiros articuladores políticos nas comunidades em que trabalham. (SILVA, 2001, p. 140).

Do outro, aparece o promotor de gabinete, isto é, o “agente judiciário cuja prioridade é o trabalho 'processual' - propor e acompanhar medidas judiciais - e cuja ação na defesa dos interesses metaindividuais se dá, sobretudo, pela via judicial” (SILVA, 2001, p. 140, grifo da autora). Tanto para Silva quanto para Coslovsky, o principal fator que diferencia esses dois tipos de procuradores são as estratégias acionadas por eles: enquanto promotores de gabinete tendem a preferir ações judiciais, promotores de fato geralmente utilizam-se de meios extrajudiciais, como negociações e processos administrativos. Seu objetivo principal, afinal, é solucionar problemas.

Pouco foi dito, no entanto, sobre as diferentes motivações de procuradores. Que tipos de problemas eles buscam resolver e por quê? Apesar de Silva (2001, p. 138) argumentar que procuradores de fato se tornam "articuladores políticos” e priorizam “questões que abrangem um grande número de pessoas ou que estejam ligadas a políticas e programas públicos”, ela não mergulha

20 "Most managerial policies adopted by the MP reward diligence and consistency rather than creativity, and cautious case-processing rather than creative problem-solving." (COSLOVSKY, 2011, p. 75-76).

${ }^{21}$ A diferença entre promotores e procuradores refere-se ao âmbito no qual eles têm competência para atuar: promotores atuam no âmbito estadual, e procuradores no federal. 
a fundo em que tipos de questões são essas. Uma pergunta central para a compreensão desse órgão conhecido como "defensor público da sociedade" (ARANTES, 2002, p. 192), portanto, seria identificar os interesses sociais que os procuradores buscam defender (CRAWFORD, 2008, p. 627). No caso de Belo Monte, argumento que as diferenças entre procuradores não dependem apenas das estratégias e recursos que eles acionam, mas de suas motivações e percepções em torno do que significa ser um procurador da república.

\section{Lutando criativamente por causas: Procuradores ativistas no caso de Belo Monte}

Alguns procuradores vieram com mais sangue nos olhos para fazer o trabalho deles. E alguns procuradores tiveram uma atuação mais protocolar, não estavam com tanto sangue nos olhos. (Entrevista 76, Instituto Socioambiental, 2016).

Ao entrevistar membros de organizações de movimentos sociais em Belém e Altamira, logo percebi que o MPF era um grande aliado em suas lutas antibarragem e por melhores políticas de compensação. Para alguns, o MPF era “sempre parceiro" (Entrevista 42, Movimento dos Atingidos por Barragens, 2016). Outros ressaltam que "se hoje tem MPF, foi uma luta nossa junto também ao MPF para que tivesse aqui nessa região" (Entrevista 26, Movimento Xingu Vivo Para Sempre, 2016). No entanto, grande parte dos entrevistados, quando perguntados sobre sua percepção acerca do MPF, ressaltava o trabalho de alguns procuradores específicos, evitando generalizar. Era comum que lideranças e/ou comunidades atingidas ressaltassem o "engajamento" (Entrevista 30, Conselho Indigenista Missionário, 2016) ou o “compromisso” de determinados procuradores (Entrevista 34, Fundação Viver, Produzir e Preservar, 2016). Mas não era bem assim com todos os procuradores: “Muitas vezes não é o MPF, também depende das pessoas, então a gente já se deparou aqui com gente do MPF completamente avesso às lutas sociais” (Entrevista 18, Federação de Órgãos para Assistência Social e Educacional, 2016).

As entrevistas com procuradores corroboram essa percepção. Alguns desses procuradores desenvolveram compromissos com as lutas de 
comunidades afetadas pela barragem, tornando a luta pelo direito à compensação o motor central de seu trabalho. Chamo esses procuradores de ativistas. O conceito de ativismo é estruturado, segundo Abers (2019), em duas dimensões: o compromisso que atores constroem com determinadas causas e sua proatividade - e criatividade - ao lutar por elas.

A primeira dimensão se refere ao aspecto ideacional do ativismo. No caso de Belo Monte, a variação em torno desse eixo entre procuradores ativistas e protocolares era notável. Todos os procuradores ativistas mobilizaram a defesa de comunidades afetadas como a motivação central de seu trabalho - bem como a justificativa para uma presença tão intensa do MPF naqueles casos. Para algum deles, lutar por esses grupos é uma "missão de vida” (Entrevista 79, MPF, 2017). Outros entendiam que “o MPF lá em Altamira tinha uma função fundamental de dar voz à população” (Entrevista 77, MPF, 2017), de ser "o braço jurídico desse movimento [de atingidos por barragens]” (Entrevista 1, MPF, 2012).

Procuradores protocolares, por outro lado, buscavam se distanciar de qualquer tipo de vínculo ideacional, geralmente ressaltando a imparcialidade que rege o cargo de procurador e sua missão de fazer com que a lei seja cumprida. Como explica uma das entrevistadas: "É o nosso papel garantir que as coisas sejam feitas na legalidade, na minha opinião. É diferente de alguma coisa voltada a determinado lado” (Entrevista 53, MPF, 2016). De acordo com outro procurador, o MPF

deve garantir que a Constituição seja respeitada. A política em sua essência não faz parte do trabalho do MPF, porque política é sobre fazer leis, e o nosso papel é fazer com que elas sejam cumpridas. (Entrevista 81, MPF, 2018).

Nessa percepção, os procuradores não podem "se opor a um projeto político de poder, porque isso aí já vai para o campo da política”; pelo contrário, eles "têm que ser técnicos e objetivos e [...] ter uma visão equidistante da questão”, não podendo “adentrar no campo do comprometimento com aquele ou este movimento social” (Entrevista 28, MPF, 2016). Diferentemente de seus colegas ativistas, procuradores protocolares não se enxergam como atores compromissados. No entanto, o ativismo não envolve apenas essa dimensão ideacional, mas também um comportamento 
proativo (KELLY, 1999; PETTINICCHIO, 2012). Nessa segunda dimensão do ativismo, também encontrei grande variação.

Uma das principais armas de procuradores no caso de Belo Monte foram as ações judiciais. De fato, entre 2001 e 2016 procuradores (ativistas e protocolares) ajuizaram 25 ações. Apesar de não ser possível comparar sistematicamente esses dois tipos de procuradores nas Ações Civis Públicas (ACPs) - visto que $75 \%$ delas (20) foram assinadas por múltiplos procuradores ${ }^{22}$-, encontramos importantes padrões ao analisar seu conteúdo. As ações ajuizadas foram analisadas por meio do software NVivo 10 e classificadas em termos dos argumentos levantados por procuradores e das demandas que eles faziam.

A análise de conteúdo revelou que $84 \%$ das ações (21) mencionavam impactos em comunidades afetadas. Algumas das ações foram elaboradas especificamente para lidar com impactos em grupos sociais, como a ACP que buscava garantir o cumprimento de condicionante para os Jurunas do km $17 .{ }^{23}$ Em outras ações, esses impactos apareciam tangencialmente, tais como em ACP que tratava sobre os efeitos decorrentes de problemas na elaboração do Estudo de Impacto Ambiental. ${ }^{24}$ Procuradores buscavam proteger essas populações de diferentes maneiras, às vezes por meio de demandas mais disruptivas como, por exemplo, exigindo a suspensão do projeto (mencionado 2 vezes), exigindo mudanças nas políticas de compensação (13), inclusão de outros grupos nessas políticas (5) ou, ainda, o cumprimento de políticas de compensação já existentes (15). ${ }^{25}$ Em resumo, isso sugere que procuradores prestavam atenção especial às comunidades afetadas. Os efeitos dessas ações judiciais, contudo, foram bastante limitados. Embora diversas das ações tivessem conseguido paralisar o processo de implementação da usina por alguns dias, elas foram derrubadas em decisões judiciais posteriores (Entrevista 21, MPF, 2016), principalmente devido à suspensão de segurança, mecanismo

22 De acordo com entrevistados, essa era uma estratégia deliberada para fortalecer a credibilidade das ações (Entrevista 21, MPF, 2016).

${ }^{23}$ ACP n $^{\circ}$ 1655-16.2013.4.01.3903.

${ }^{24}$ ACP n $^{0} 25999-75.2010 .4 .01 .3900$.

${ }^{25}$ Cumpre lembrar que diversas das ações tinham múltiplas demandas, o que significa que usei mais de uma categoria para classificá-las. 
que interrompe o julgamento do mérito de ações judiciais por se tratar de um projeto de “interesse nacional” (Entrevista 11, MPF, 2015).

Quando olhamos para além dos tribunais, começamos a perceber algumas características que distinguem procuradores ativistas e protocolares. A fim de contornar os obstáculos do poder judiciário, tanto procuradores ativistas como protocolares buscavam acionar táticas extrajudiciais. Procuradores protocolares revelaram que eles constantemente negociavam com a Norte Energia e se utilizavam do inquérito civil como mecanismo de negociação. Procuradores ativistas, no entanto, davam um passo a mais. Quando os instrumentos tradicionais falhavam, eles iam além e acionavam táticas criativas.

Um exemplo é a articulação de procuradores ativistas para coordenar uma audiência pública na tentativa de convencer a Defensoria Pública da União (DPU) a se instalar na cidade de Altamira para lidar com os problemas de reassentamento de grupos atingidos por Belo Monte. ${ }^{26}$ Indivíduos afetados pela usina bateram à porta do MPF à medida que estavam sendo forçados a deixar suas casas, que seriam alagadas pela usina. Mas esse "não é caso para o MP, era caso para a Defensoria Pública. Quem trata do individual é a defensoria. No MP a gente trata de [...] casos que são coletivos. Só que a Defensoria Pública não estava lá” (Entrevista 14, MPF, 2016). Comovida com o sofrimento desses indivíduos, a procuradora ativista organizou uma audiência pública cujo objetivo

era trazer a Defensoria Pública da União para Altamira, porque não tinha Defensoria Pública, e o resultado foi esse, hoje eles estão lá [...] porque a opção foi justamente tratar de uma maneira diferente [e não ajuizar uma ação]. (Entrevista 14, MPF, 2015).

Outro exemplo é o caso dos ribeirinhos. Como a Norte Energia se recusava a compensar as duas casas que os ribeirinhos tradicionalmente

${ }^{26}$ Até 2015, Altamira não tinha um escritório da Defensoria Pública da União, apenas uma sede da Defensoria Pública do Estado do Pará que, apesar de também ter atuado no caso de Belo Monte, permaneceu quase inativa durante alguns anos pela falta de defensores na região (Entrevista 55, Defensoria Pública do Estado do Pará, 2016). 
têm - uma ao longo do rio e outra na cidade - a procuradora ativista organizou uma inspeção interinstitucional, convocando membros da comunidade acadêmica, de OMSs e de outras agências estatais para observar, no próprio local onde os povos ribeirinhos habitavam, a realidade do processo de desapropriação desse grupo. Ela conta que

a ideia da inspeção foi isso: a gente não tem condições de ouvi-los numa audiência pública. [...] Então a ideia foi ir para os locais deles para que eles pudessem falar nas condições, no tempo deles. (Entrevista 67, MPF, 2016).

Esses casos revelam uma diferença crucial entre procuradores ativistas e protocolares: apesar de ambos lançarem mão de estratégias extrajudiciais, procuradores ativistas eram persistentes e utilizavam táticas criativas para alcançar seus objetivos. Procuradores protocolares, no entanto, não concebiam ou usavam táticas criativas que fugissem do repertório de ação tradicionalmente associado ao trabalho de procuradores (Entrevistas 28 e 53, MPF, 2016; Entrevista 81, MPF, 2018). Apesar de também atuarem em problemas relacionados ao caso de Belo Monte, procuradores protocolares não se mostravam proativos para resolver os obstáculos que enfrentavam, tampouco priorizavam o caso. Vemos, portanto, que as ações e motivações de procuradores ativistas e protocolares são bastante diferentes. Mas o que explica essa variação?

\section{Trajetórias e socialização organizacional}

Estudos anteriores encontraram evidências que ativistas institucionais já eram ativistas antes de entrarem nas instituições em que trabalhavam (GAGNE, 1996; RAEBURN, 2004; BANASZAK, 2010; HYSING; OLSSON, 2017). No caso de Belo Monte, trajetórias não tiveram alto poder explicativo no ativismo engajado de procuradores. Dos cinco procuradores ativistas entrevistados, apenas um deles tinha envolvimento prévio com lutas de grupos atingidos por barragens (e com atividades relacionadas a movimentos sociais de maneira geral). Ele explica: 
Não foi o Ministério Público que me escolheu, fui eu que escolhi. Eu quero defender a população tradicional da Amazônia. Onde é que eu posso fazer isso melhor? Na advocacia? Não. Na defensoria? Não. No MPF. Aqui é o lugar por excelência onde se faz essa defesa, então eu disse: eu quero ir para aí. Então quando eu passo no concurso, já foi completamente direcionado, que aqui eu ia cumprir a minha missão. (Entrevista 79, MPF, 2017).

Nesse caso, fica claro como o procurador já chega ao MPF altamente compromissado com causas de grupos atingidos por grandes empreendimentos. Todos os outros procuradores ativistas, contudo, não eram ativistas antes de entrar para o MPF. Na realidade, procuradores evitavam ir para o MPF de Altamira devido ao alto custo de vida da cidade (Entrevista 12, MPF, 2015). Um procurador que se identificava com comunidades ribeirinhas afirmou que "a maioria dos procuradores [que vinha para Altamira] chegava do Sul, com uma realidade completamente diferente” (Entrevista 79, MPF, 2017). Portanto, eles tinham pouca ou nenhuma experiência com lutas de comunidades tradicionais, como povos indígenas ou ribeirinhos. Mas como eles desenvolvem compromissos após adentrarem o MPF?

Outra variável explicativa é o contexto organizacional no qual procuradores são socializados. A ideia por trás dessa hipótese é de que a socialização em um contexto organizacional que promove ativismo aumenta as chances de atores se tornarem ativistas (KATZENSTEIN, 1998; SCULLY; SEGAL, 2002; FILLIEULE, 2010). Em estudo sobre procuradores em São Paulo, Coslovsky (2011) argumenta que o ativismo de procuradores pode ser explicado por estruturas e processos organizacionais. Minha pesquisa mostrou que apesar do contexto organizacional ser um passo importante no desenvolvimento de compromissos, ele não é uma condição suficiente para engajamento no ativismo.

Todos os procuradores ativistas afirmaram que o MPF no Pará tinha um ethos diferente dos outros escritórios do MPF. Como mencionado anteriormente, procuradores no Brasil são geralmente treinados para esconder suas motivações políticas. Procuradores entrevistados disseram que sua experiência no Pará havia sido diferente, e que o MPF nesse estado era majoritariamente progressista e crítico à construção de hidrelétricas na 
Amazônia (Entrevista 21, MPF, 2016). Na realidade, mesmo antes de BM, o escritório do MPF em Belém já se mostrava altamente preocupado com a construção de hidrelétricas. Na época (2001), não havia escritório do MPF em Altamira. O MPF instalou uma sede em Altamira em $2006^{27}$ e, desde então, a maioria do trabalho relacionado a BM foi transferido de Belém para lá. Procuradores de Belém, contudo, permaneceram ativos no caso, principalmente por causa dos seus compromissos para ajudar comunidades afetadas (Entrevista 21, MPF, 2016; Entrevista 79, MPF, 2017).

Além disso, procuradores de Belém buscavam ajudar seus colegas de Altamira devido às altas taxas de rotatividade no escritório daquele município. ${ }^{28}$ De acordo com um deles,

foi por isso [rotatividade da PRM-Altamira] que nós dois nos mantivemos sempre tão ligados ao tema, para fazer essa memória. Independentemente de quem fosse o procurador que estava lá, a gente ajudava na transmissão até ele se empoderar daquele conhecimento e tocar sozinho. (Entrevista 21, MPF 2016).

Procuradores criaram inclusive um "grupo de trabalho" para discutir questões relacionadas a Belo Monte (Entrevista 79, MPF, 2017), estabelecendo assim "relações muito próximas e cooperativas" entre procuradores de Belém e Altamira (Entrevista 77, MPF, 2017). Como explica um dos procuradores:

Eu não consigo imaginar uma equipe como essa, engajada, capacitada. [...] Existe dentro do MP uma sensibilidade muito grande com relação a Belo Monte, a ponto de você ter um grupo, um centro de apoio, então você nunca está

27 A criação do escritório em Altamira foi motivada por intensos conflitos agrários e violência contra ativistas locais (Entrevista 78, MPF, 2016).

28 “O MPF de Altamira era considerado um gabinete de 'primeira lotação’ porque era habitado principalmente por procuradores recém-admitidos no MPF. A falta de infraestrutura da cidade, somada aos altos preços - principalmente após a construção da usina - não criava incentivos para procuradores escolherem vir para Altamira. Por isso, procuradores que iam para Altamira geralmente saíam quando tinham a oportunidade, e novos procuradores chegavam à cidade a cada dois anos em média.” (Entrevista 12, MPF, 2015). 
sozinho. Eu acho que isso talvez não aconteça em outras hidrelétricas, que às vezes o procurador fica lá mais sozinho. (Entrevista 14, MPF, 2015).

Procuradores em Belém não somente providenciavam suporte e ajudavam seus pares na análise dos casos em que trabalhavam, mas também socializavam seus colegas em um ambiente que problematizava a implementação de Belo Monte - bem como a construção de barragens de maneira geral - e enfatizava os impactos causados em grupos sociais locais. Um dos procuradores explica:

Como eu fazia, por exemplo, com os procuradores que chegavam do Sul, com uma realidade completamente diferente? Sabe qual era a tática? "Vai para a aldeia. Fica na aldeia”. [...] E quando voltava, voltava completamente mudado. Não tem pedagogia melhor do que essa de conhecer a realidade. $\mathrm{O}$ choque de realidade que levava era o suficiente para o cara vir e preparar a ação contra Belo Monte. (Entrevista 79, MPF, 2017).

Procuradores da PRM-Altamira eram, portanto, socializados em um ambiente que problematizava a implementação de BM e, ao mesmo tempo, ressaltava os impactos que a usina trazia a grupos atingidos. Procuradores entrevistados revelaram que esse suporte foi fundamental para que eles entendessem a complexidade das lutas políticas que estavam em jogo (Entrevistas 12 e 14, MPF, 2015). Isso parece apoiar a hipótese de que o engajamento no ativismo pode resultar de uma socialização organizacional (FILLIEULE, 2010; COSLOVSKY, 2011). No entanto, apesar de serem socializados em um ambiente que promovia o desenvolvimento de compromissos com causas relacionadas às lutas de grupos atingidos, nem todos os procuradores se tornaram ativistas. Durante minha última pesquisa de campo, em 2016, havia três procuradores trabalhando na PRM-Altamira. Desses três, um era claramente ativista, tendo inclusive recusado a possibilidade de sair de Altamira duas vezes para continuar atuando no caso de Belo Monte. Os outros dois, no entanto, se identificavam mais como neutros e imparciais (protocolares). Uma análise comparada entre esses 
procuradores nos permite, assim, dar mais um passo na compreensão sobre como servidores públicos se tornam ativistas. Os três procuradores não tiveram qualquer contato com lutas antibarragem ou experiências que os levassem a criar disposições para o ativismo antes de suas chegadas a Altamira. Além disso, eles foram socializados no mesmo ambiente organizacional. Afinal, o que explica o fato de alguns atores se tornarem ativistas e outros não quando "controlamos” pelas trajetórias e socialização organizacional?

\section{Descobertas e mediações}

A comparação entre os procuradores de Altamira revelou que o grau com que interagiam com comunidades afetadas e organizações de movimentos sociais variava dramaticamente. Durante minha ida à campo percebi, gradualmente, que grande parte dos grupos afetados entrevistados comunicava a procuradora ativista quando buscavam avançar suas demandas. Nas entrevistas, perguntava a membros de organizações de movimentos se eles haviam mantido algum tipo de relação com o MPF nos últimos anos em relação ao caso de Belo Monte. Em caso afirmativo, indagava-lhes com quais procuradores eles interagiam. Ao todo, entrevistei 36 ativistas de OMS em 2016 na cidade de Altamira, dos quais 26 informaram já ter interagido com a procuradora ativista. Ambos os procuradores protocolares, no entanto, só foram mencionados por 2 entrevistados cada um. Mas por que exatamente essas interações importam? E que tipo de interações procuradores estabelecem? As entrevistas e a observação de reuniões revelaram que procuradores estabelecem majoritariamente dois tipos de interação, que chamo aqui de descobertas e mediações.

Entendo por descobertas as práticas comunicativas nas quais procuradores ficam cientes dos problemas enfrentados por grupos afetados. À medida que descobrem os impactos que antes eram invisíveis, eles internalizam as demandas desses grupos e as colocam no topo de sua agenda. Já mediações dizem respeito às práticas comunicativas em que procuradores levam as demandas de grupos atingidos para as negociações com tomadores de decisão como, no caso de BM, em reuniões com funcionários da Norte Energia e servidores do Ibama e da Funai, responsáveis 
pela implementação da usina. ${ }^{29}$ Por meio de dessas práticas de mediação, procuradores solidificaram seus compromissos com as causas de grupos afetados, geralmente entendendo de quem era a culpa pelos problemas causados a essas comunidades. A figura 1 resume os processos pelos quais procuradores se tornavam ativistas.

Figura 1: Processos de engajamento em ativismo

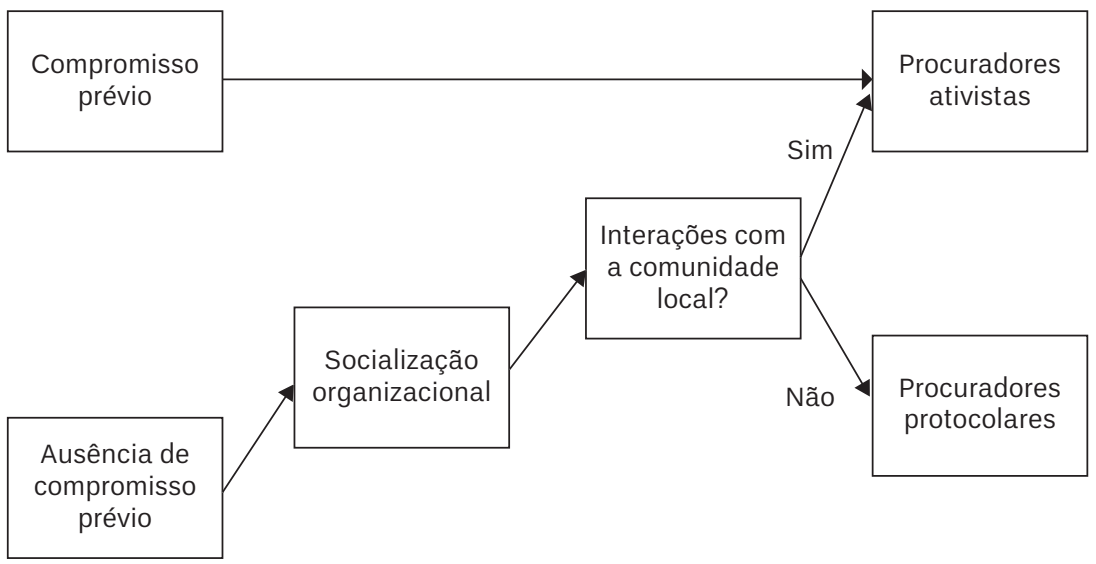

Como podemos ver, compromissos prévios são condições suficientes para o ativismo. Contudo, não foi uma variável com alto poder explicativo neste caso, visto que apenas um dos procuradores já se encontrava engajado com minorias étnicas antes de entrar para o MPF. Todos os outros procuradores que se tornaram ativistas seguiram um caminho similar: após serem socializados em uma organização que promovia o engajamento em comportamentos ativistas, eles interagiram com a comunidade local por meio de práticas de descobertas e mediações que os levaram a desenvolver e manter compromissos com as causas de grupos afetados pelo empreendimento.

${ }^{29}$ O conceito de mediação - também conhecido como brokerage - envolve a conexão entre dois ou mais atores previamente desconectados (MCADAM; TARROW; TILLY, 2001), ou parcialmente desconectados (MISCHE, 2008). Procuradores podem ser entendidos como mediadores à medida que conectam grupos afetados com outros atores que esses grupos não conseguiam atingir ou se sentiam ignorados por eles. 
Procuradores protocolares, apesar de serem socializados em um contexto organizacional semelhante, não mantiveram interações constantes com grupos afetados. Em outras palavras, práticas de descobertas e mediações não faziam parte de sua rotina de trabalho.

Todos os procuradores ativistas entrevistados interagiam constantemente com grupos afetados, ouvindo suas queixas e demandas e negociando com outros atores estatais envolvidos na implementação da usina. O MPF de Altamira, na realidade, se tornou o único aliado estatal dos grupos afetados e depositário de todas as suas esperanças, visto que esses grupos encontravam grande dificuldade de acesso à Norte Energia e a outros órgãos estatais, como o Ibama ${ }^{30}$ e a Funai. ${ }^{31}$ Insulados dos processos de negociação e decisão sobre Belo Monte, esses grupos voltaram sua atenção para o MPF, bombardeando procuradores com denúncias e informações sobre violações de direitos.

As entrevistas com procuradores ativistas revelaram que por meio das práticas de descobertas e mediações, eles internalizavam as demandas desses movimentos, construindo compromissos para lutar por suas causas. A procuradora ativista trabalhando em Altamira em 2016, por exemplo, contou que seu esforço em coordenar uma audiência pública na tentativa de convencer a Defensoria Pública a instalar uma sede em Altamira surgiu a partir da interação com grupos afetados:

Quando foi em setembro do ano passado [2014], me procurou uma senhora falando que ela queria uma casa, mas eles só estavam dando indenização, que a indenização para ela não dava, porque ela não conseguia comprar outra casa, e ela queria uma casa. [...] Aí eu falei para essa senhora: "a senhora espera lá fora, que eu vou com a senhora lá na empresa, pessoalmente”. [...] Aí cheguei com ela lá, aí como que funcionava na empresa,

${ }^{30}$ Até o final de 2015 - após a concessão da Licença de Operação (LO) de Belo Monte - o Ibama, por exemplo, não tinha nenhum servidor em Altamira que lidasse com o caso de Belo Monte. Consequentemente, diversos grupos da sociedade civil não conseguiam dialogar com o órgão: “você não tinha acesso ao Ibama, só via o prédio” (Entrevista 24, MXVPS, 2016).

31 Já a Funai, apesar de ter uma sede em Altamira envolvida no processo de Belo Monte, vive com pouquíssimos recursos: "Hoje se você chega dentro da Funai, para beber uma água tem que comprar, fazer vaquinha. Porque não tem recurso” (Entrevista 70, FUNAI, 2016). 
eu vi o seguinte: [...] a pessoa chega, aí ela recebe um papel com a avaliação da casa, quanto ela vai receber [...] Então não tem negociação nenhuma, porque você tem que aceitar o que eu estou te impondo. [...] Então quando eu vi isso, eu tive a nítida percepção de que a Norte Energia estava fazendo o papel dela, a Norte Energia é o empreendedor. Quem não estava lá era o Estado, quem não estava lá era a assistência jurídica gratuita que essa pessoa tinha que ter no momento da negociação. Então o erro estava aí. Então a audiência pública, o objetivo dela foi trazer o Estado para acompanhar as pessoas nas negociações. (Entrevista 14, MPF, 2015).

Podemos ver, portanto, como práticas comunicativas de descobertas foram o gatilho para o desenvolvimento de compromissos a favor dessas causas. Embora fosse apenas responsável por trabalhar em casos coletivos, descobrir a situação de remoção compulsória desses grupos levou a procuradora a se comprometer com a luta por melhores condições de reassentamento para eles, trazendo assistência jurídica para essas pessoas (Entrevista 14, MPF, 2015). O compromisso dessa procuradora foi fortalecido à medida que ela atuou como mediadora de conflitos de grupos afetados e tomadores de decisão no processo da usina. Uma das reuniões que observei ilustra esse efeito. Alguns dias antes da reunião, membros de OMSs entraram em contato com a procuradora, revelando que a empresa Norte Energia se recusava a fazer a manutenção dos equipamentos adquiridos para Unidades Básicas de Saúde (UBS) em povos indígenas. A procuradora, espantada, agendou uma reunião com funcionários da Norte Energia, chamando também representantes da Funai e da sociedade civil. Durante essa reunião, a procuradora perguntou aos funcionários da NE se eles cuidariam da manutenção dos equipamentos. Eles se negaram e disseram que isso era uma decisão da diretoria. A procuradora então disse que estava extremamente preocupada que essas UBS se tornassem “elefantes brancos” com nenhuma utilidade, ressaltando que o MPF e a NE teriam "uma discordância visceral nesse assunto" e que poderia ajuizar uma ACP incluindo danos morais caso a posição da empresa não mudasse. Por meio dessa prática de mediação, a procuradora então fortaleceu seu compromisso com comunidades indígenas que não estavam recebendo cuidados de saúde apropriados. 
Quando voltamos um pouco no tempo, vemos que interações - tanto práticas de descobertas como de mediações - foram descritas como relevantes por todos os procuradores ativistas entrevistados (que trabalharam no caso antes de minha ida à campo em 2016). A primeira ACP ajuizada pelo MPF no caso de BM em 2001, por exemplo, surgiu a partir de uma prática de descoberta na qual um procurador ativista visitou o povo indígena Juruna:

[...] a primeira ação de BM vai ser proposta depois de uma viagem minha à aldeia dos Juruna, na terra indígena Paquiçamba. [...] Quando eu vou nessa viagem ao Paquiçamba, um dos indígenas chega no meio da reunião com o que eles chamavam de palco de números, que era uma régua métrica. E tira aquela régua métrica da beira do rio e me entrega. Todo mundo ficou extremamente preocupado na reunião. [...] E aí quando eu volto para a procuradoria e faço as primeiras investigações [...] já estava sendo construída a terceira maior hidrelétrica do mundo já no final do EIA-Rima [Estudo de Impacto Ambiental/Relatório de Impacto Ambiental]. E aí foi a primeira ação. (Entrevista 79, MPF, 2017).

Podemos ver que, à medida que procuradores interagiam com comunidades afetadas pelo empreendimento, eles passaram a descobrir os impactos causados a esses grupos. De fato, todos os procuradores ativistas entrevistados ressaltaram a importância dos laços que eles desenvolveram com grupos afetados e organizações de movimentos sociais. Um dos procuradores ativistas explica:

A nossa relação com movimentos sociais [...] influencia a forma de desenvolver o pensamento, influencia a forma como vejo o direito, a forma como manuseio. [...] A relação com os movimentos sociais ajuda muitas vezes a abrir a cabeça do sujeito: “olha, o mundo urbano não é o único que existe. Tem esse mundo aqui que eu também tenho que entender”. (Entrevista 21, MPF, 2016).

Outro procurador ativista concorda: 
Acho que é fundamental dentro do MPF, sair do seu gabinete para entender a sociedade que te cerca. [...] A lógica do movimento social é fundamental porque a sociedade organizada te dá mobilidade na informação, [...] então acho que isso é fundamental. Tinha uma relação muito próxima deles. (Entrevista 77, MPF, 2017).

E ainda outro procurador ativista complementa:

a cabeça pensa onde os pés pisam. [...] Acho que um contato com a realidade local, você tem que ter, acho que isso que diferencia a atuação. Se você tem um contato com a realidade local, sua atuação muda. (Entrevista 78, MPF, 2017).

No caso de BM, práticas de descobertas e mediações faziam parte da rotina de procuradores ativistas, levando-os a desenvolver e manter compromissos com as comunidades afetadas pela usina. Procuradores protocolares, por outro lado, não interagiam com tanta frequência com grupos afetados ou com OMSs. Os próprios procuradores ativistas reconhecem que existe uma diferença na maneira como seus colegas abordam o trabalho na procuradoria:

Tem um pouco da personalidade de cada um, tem gente que é mais aberto ao diálogo, outros são mais fechados, gostam de trabalhar dentro do gabinete, receber a questão estritamente jurídica, só que eu não consigo dissociar a ideia da questão jurídica da questão social e política local. (Entrevista 77, MPF, 2017).

Entrevistas com organizações de movimentos sociais e grupos afetados corroboram com essa disparidade. Um dos membros da Cooperativa Mista dos Garimpeiros da Ressaca, Itata, Galo, Ouro Verde e Ilha da Fazenda (Coomgrif) conta que

nunca consegui falar com o [procurador]. Quando eu tentei falar com o [procurador], esse ano [2016], primeiro ele está de licença, depois voltou, aí encontrei com o [procurador], falei que tinha tentado falar com ele, estou aguardando até hoje. (Entrevista 48, COOMGRIF, 2016). 
Entrevistas com procuradores protocolares revelaram que eles não eram tão proativos quanto seus colegas ativistas. Sua rotina geralmente envolvia ficar dentro do gabinete. Apesar de interagirem às vezes com grupos afetados e movimentos, práticas de descobertas e mediação não faziam parte de sua rotina.

Figura 2: Processo de desenvolvimento de compromissos com minorias étnicas

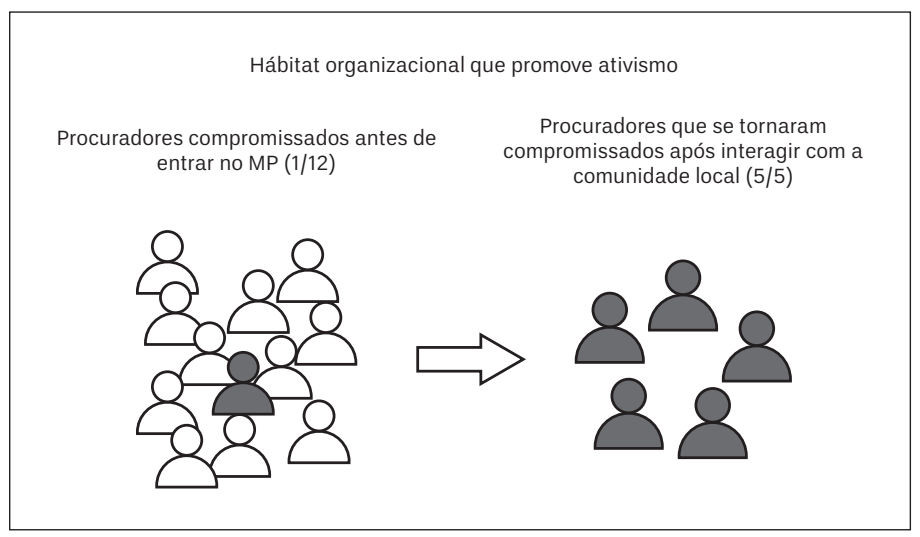

Para resumir, interações - e, mais especificamente, práticas de descobertas e mediações - são importantes porque, por meio delas, procuradores internalizam as demandas de grupos afetados, desenvolvendo e fortalecendo compromissos para defendê-los. A figura 2 resume o argumento deste capítulo. Ao contrário do que previam estudos anteriores (BANASZAK, 2010; HYSING; OLSSON, 2017), mostrei que ativistas institucionais não necessariamente entram para o Estado com compromissos prévios. A maior parte dos procuradores ativistas desenvolveu compromissos com causas após terem entrado no MPF. Situados em um contexto organizacional que promove ativismo, cinco procuradores saíram de seus gabinetes e passaram a interagir constantemente com a comunidade local, desenvolvendo e mantendo compromissos para lutar por suas causas. 


\section{Considerações finais}

Estudos sobre ativistas institucionais tendem a explicar o compromisso desses ativistas a partir de duas variáveis: disposições prévias, ou seja, a ideia de que burocratas já são ativistas antes de entrarem na administração pública, e socialização organizacional. Oberfield (2014) chama essas perspectivas de “disposicional” e "institucional”. Seu estudo argumenta que temos que olhar para esses dois fatores para entender a motivação de burocratas. Neste capítulo, mostrei que burocratas podem se tornar ativistas apesar de não terem disposição para isso. Mostrei ainda que a socialização organizacional não foi uma condição suficiente para o engajamento em comportamentos ativistas. Argumento neste trabalho que procuradores se engajavam no ativismo à medida que interagiam com a comunidade local, descobrindo seus problemas e mediando suas disputas. Por meio dessas práticas comunicativas, procuradores internalizaram os conflitos de comunidades afetadas, colocando-os em posição de evidência em suas agendas. Nesse sentido, este trabalho contribui para a literatura de ativismo institucional porque evidencia um caminho alternativo por meio do qual atores estatais podem se engajar em causas: a partir das interações que estabelecem com outros atores dentro e fora do Estado. Estudos futuros poderão investigar melhor o impacto de contextos organizacionais ao comparar ativistas institucionais situados em diferentes tipos de organização (que promovam ou desencorajem comportamentos ativistas, por exemplo).

Ao mostrar como procuradores se tornaram mediadores e desenvolveram compromissos com causas, este capítulo também contribui para o debate em torno dos mecanismos de mediação (também conhecido como brokerage). Diferentemente de estudos anteriores, que abordam como a mediação facilita processos de comunicação ou a criação de novos atores coletivos (MCADAM; TARROW; TILLY, 2001), foquei nos impactos não em quem é mediado, mas nos próprios atores que executam o papel de mediador. O potencial de gerar compromissos da mediação também coloca em xeque visões de mediadores como atores neutros (SABATIER, 1998) ou guiados por interesse próprio (INGOLD; VARONE, 2012), indicando que as motivações de brokers são melhor compreendidas não como premissas, mas como perguntas empíricas contextualmente situadas. 
Ademais, a trajetória que transforma procuradores em ativistas aqui exposta abre caminhos para o debate sobre como movimentos afetam o Estado e, mais especificamente, como movimentos fazem uso de instituições do sistema legal para promover suas agendas (ZEMANS, 1983; MCCANN, 1994). A crescente literatura sobre legal mobilization tem demonstrado que arenas legais emergiram como espaços-chaves por meio dos quais movimentos buscam produzir mudanças (LOSEKANN, 2013). Neste capítulo, expus como mobilizar e engajar procuradores pode ser uma tática eficiente para as OMSs. Em um caso no qual ações diretas - como protestos e ocupações - tiveram sucesso limitado, adiando a construção da usina por apenas alguns anos (Pereira, 2014), o trabalho de procuradores foi crucial para garantir que comunidades ribeirinhas afetadas pela usina fossem, pela primeira vez na história do Brasil, reassentadas na beira do rio, mantendo as condições de vida que tinham antes da barragem.

\section{Referências}

ABERS, Rebecca Neaera. Bureaucratic activism: pursuing environmentalism inside the Brazilian state. Latin American Politics and Society,v. 66, n. 2, p. 22-44, mai 2019.

ABERS, Rebecca Neaera; TATAGIBA, Luciana. Institutional Activism: Mobilizing for Women's Health from Inside the Brazilian Bureaucracy. In: ROSSI, Frederico; von BULOW, Marisa. Social Movement Dynamics: New Perspectives on Theory and Research from Latin America. New York: Routledge, 2015. p. 73-104.

ARANTES, Rogério Bastos. Ministério Público e Política no Brasil. São Paulo: Sumaré, 2002.

ARANTES, Rogério Bastos. Ministério Público na fronteira entre a Justiça e a Política. Justitia, São Paulo, v. 64, n. 197, p. 325-335, dez. 2007.

BANASZAK, Lee Ann. The women's movement inside and outside the State. New York: Cambridge University Press, 2010. 
BECKER, Howard S. Tricks of the trade. Chicago: University of Chicago Press, 1998.

BERMANN, Célio. O projeto da usina hidrelétrica Belo Monte: a autocracia energética como paradigma. Novos Cadernos NAEA, Belém, v. 15, n. 1, p. 5-23, jun. 2012.

BINDER, Amy J. Contentious Curricula: Afrocentrism and creationism in American public schools. Princeton: Princeton University Press, 2002. CASTILHO, Sérgio; LIMA, Antônio Carlos Souza; TEIXEIRA, Carla C. (Orgs). Antropologia das práticas de poder: reflexões etnográficas entre burocratas, elites e corporações. Rio de Janeiro: Contra Capa, 2014.

COSLOVSKY, Salo. Compliance and competitiveness: How prosecutors enforce labor and environmental laws and promote economic development in Brazil. Doctoral Dissertation. Massachusetts Institute of Technology, Massachusetts, 2009.

COSLOVSKY, Salo. Relational regulation in the Brazilian Ministério Publico: the organizational basis of regulatory responsiveness. Regulation and Governance, v. 5, n. 1, p. 70-89, Mar. 2011.

CRAWFORD, Colin. Defending public prosecutors and defining Brazil's (environmental) "public interest”: a review of Lesley McAllister’s "Making law matter: environmental protection and legal institutions in Brazil”. The George Washington International Law Review, v. 40, n. 3, p. 619-647, jan. 2008.

DÓRIA, Pedro. Energia no Brasil e dilemas do desenvolvimento: a crise mundial e o futuro. Petrópolis: Vozes, 1976.

EISENSTEIN, Hester. Femocrats, official feminism, and the uses of power: a case study of EEO implementation in New South Wales, Australia. Yale Journal of Law \& Feminism, v. 2, n. 1, p. 51-73, 1989.

FILLIEULE, Olivier. Some elements of an interactionist approach to political disengagement. Social Movement Studies, v. 9, n. 1, p. 1-15, 2010. 
GAGNE, Patricia. Identity, strategy, and feminist politics. Social Problems, v. 43, n. 1, p. 77-93, Feb. 1996.

GAMSON, William. Commitment and agency in social movements. Sociological Forum, v. 6, n. 1, p. 27-50, mar. 1991.

HIRSCH, Eric. Sacrifice for the Cause: Group processes, recruitment, and commitment in a student social movement. American Sociological Review, v. 55, n. 2, p. 243-254, apr. 1990.

HOOGHE, Liesbet. Supranational activists or intergovernmental agents? Explaining the orientations of senior commission officials toward European integration. Comparative Political Studies, v. 32, n. 4, p. 435-463, Jan. 1999. HYSING, Erik; OLSSON, Jan. Green inside activism for sustainable development: political agency and institutional change. Palgrave: Macmillan, 2017. INGOLD, Karin; VARONE, Frédéric. Treating policy brokers seriously: evidence from the climate policy. Journal of Public Administration Research and Theory, v. 22, n. 2, p. 319-346. Apr. 2012.

JEROLMACK, Colin; KHAN, Shamus. Talk is cheap: ethnography and the attitudinal fallacy. Sociological Methods and Research, v. 43, n. 2, p. 178-209, May 2014.

KATZENSTEIN, Mary Fainsod. Faithful and fearless: moving feminist protest inside the church and military. Princeton: Princeton University Press, 1998.

KELLY, James. Bureaucratic activism and the Charter of Rights and Freedoms: the Department of Justice and its entry into the centre of government. Canadian Public Administration, v. 42, n. 4, p. 476-511, 1999.

KERCHE, Fábio. Autonomia e discricionariedade do Ministério Público no Brasil. Dados - Revista de Ciências Sociais, Rio de Janeiro, v. 50, n. 2, p. 259-279, 2007.

LEMGRUBER, Julita et al. Ministério Público: Guardião da Democracia Brasileira? Rio de Janeiro: Centro de Estudos de Segurança e Cidadania, 2016. 
LOSEKANN, Cristiana. Mobilização do Direito como Repertório de Ação Coletiva e Crítica Institucional no Campo Ambiental Brasileiro. Dados Revista de Ciências Sociais, v. 56, n. 2, p. 311-349, 2013.

MAGALHÃES, Sônia; HERNANDEZ, Francisco (org.). Painel de especialistas. Análise crítica do estudo de impacto ambiental do aproveitamento hidrelétrico de Belo Monte, 29 out., Belém, 2009.

MCADAM, Doug; TARROW, Sidney; TILLY, Charles. Dynamics of contention. Cambridge: Cambridge University Press, 2001.

MCCANN, Michael W. Rights at work: pay equity reform and the politics of legal mobilization. Chicago: University of Chicago Press, 1994.

MELUCCI, Alberto. Nomads of the present: social movements and individual needs in contemporary society. Philadelphia: Temple University Press, 1989. MEYERSON, Debra E.; SCULLY, Maureen A. Tempered radicalism and the politics of ambivalence and change. Organization Science, v. 6, n. 5, p. 585-600, Sep./Oct. 1995.

BRASIL. Ministério Público Federal. Procuradoria da República no Pará. Processo Caso Belo Monte. Tabela de acompanhamento dos processos judiciais do Ministério Público Federal contra irregularidades no projeto e construção da usina hidrelétrica de Belo Monte, no Pará. Belém, PA, mar. 2016. Disponível em: http://www.mpf.mp.br/pa/sala-de-imprensa/ documentos/2016/tabela_de_acompanhamento_belo_monte_atualizada_ mar_2016.pdf/view. Acesso em: 12 abr. 2017.

MISCHE, Ann. Partisan publics: Communication and contention across Brazilian youth activist networks. New Jersey: Princeton University Press, 2008. OBERFIELD, Zachary. Becoming bureaucrats: socialization at the front lines of government service. Philadelphia: University of Pennsylvania Press, 2014. O'LEARY, Rosemary. The ethics of dissent: managing guerrilla government. Los Angeles: Sage, 2014. 
PAUL, Gustavo. Os meninos superpoderosos. Exame, Rio de Janeiro, 31 mai. 2007. Disponível em: http://www.acendebrasil.com.br/media/ imprensa/2007_05_31_Revista\%20Exame.pdf. Acesso em: 01 mai. 2017. PEREIRA, Ana. A construção de capacidade estatal por redes transversais: o caso de Belo Monte. Tese (Doutorado em Ciência Política) - Instituto de Ciência Política, Universidade de Brasília, Brasília, 2014.

PETTINICCHIO, David. Institutional activism: reconsidering the insider/ outsider dichotomy. Sociology Compass, v. 6, n. 6, p. 499-510, Jun. 2012. PUGH, Alison J. What good are interviews for thinking about culture? Demystifying interpretive analysis. American Journal of Cultural Sociology, v. 1, n. 1, p. 42-68, 2013.

RAEBURN, Nicole. Inside out: the struggle for lesbian, gay and bisexual rights in the workplace. Minneapolis, MN: University of Minnesota Press, 2004.

RICH, Jessica. Grassroots bureaucracy: intergovernmental relations and popular mobilization in Brazil's AIDS policy sector. Latin American Politics and Society, v. 55, n. 2, p. 1-25, 2013.

SABATIER, Paul. The advocacy coalition framework: revisions and relevance for Europe. Journal of European Public Policy, v. 5, n. 1, p. 98-130, 1998.

SANTORO, Wayne A.; MCGUIRE, Gail M. Social movement insiders: the impact of institutional activists on affirmative action and comparable worth policies. Social Problems, v. 44, n. 4, p. 503-519, nov. 1997.

SCULLY, Maureen; SEGAL, Amy. Passion with an umbrella: grassroots activists in the workplace. Research in the Sociology of Organizations, v. 19, p. 125-168, 2002.

SILVA, Cátia. Promotores de justiça e novas formas de atuação em defesa de interesses sociais e coletivos. Revista Brasileira de Ciências Sociais, v. 16, n. 45, p. 127-144, 2001. 
SILVA, Marcelo; RUKOWSKI, Bianca. Condições e mecanismos do engajamento militante: um modelo de análise. Revista Brasileira de Ciência Política, n. 21, p. 187-226, 2016.

TAYLOR, Steven J; BOGDAN, Robert; DEVAULT, Marjorie. Introduction to qualitative research methods. New Jersey: John Wiley \& Sons, 1998. WEBER, Max. Economy and society: an outline of interpretive sociology. Translated by G. Roth. Berkeley: University of California Press, 1978. WEISS, Robert. Learning from strangers: the art and method of qualitative interview studies. New York: Free Press, 1995.

ZEMANS, Frances Kahn. Legal mobilization: the neglected role of the law in the political system. American Political Science Review, v. 77, n. 3, p. 690-703, 1983. 